\title{
UJI EFEK HIPOGLIKEMIK EKSTRAK TANAMAN SENDUDUK (Melastoma Malabatricum L.) PADA TIKUS PUTIH JANTAN
}

\author{
Yeni Agustin ${ }^{1}$, Edy Sapada $^{2 *}$, Mayaranti Wilsya ${ }^{3}$ \\ 1.2.3. Program Studi S1 Farmasi STIK Siti Khadijah Palembang \\ Email : yeniagustin03@gmail.com \\ edysapada@gmail.com*) \\ 1stwilsyamaya@gmail.com
}

\begin{abstract}
ABSTRAK
Tanaman senduduk merupakan tanaman yang serbaguna, mulai dari daun,bunga, dan buah dapat dimanfaatkan oleh manusia. Di dalam daun dan bunga senduduk tersebut terkandung flavonoid, dan tanin yang berfungsi sebagai antidiabetes yang dimana merupakan suatu penyakit atau gangguan metabolisme kronis dengan multietiologi yang ditandai dengan tingginya kadar gula darah. Penelitian ini bertujuan untuk mengetahui efek penurunan kadar gula darah dari ekstrak daun dan bunga senduduk (Melastoma malabatricum L). Penelitian ini merupakan penelitian eksperimental laboratorium. Pada penelitian ini subjek terbagi 5 kelompok yaitu (K+) Glibenklamid 0,0975mg, (K-) CMC 0,5\%, dan kelompok perlakuan dosis ektrak etanol daun senduduk dengan dosis yang sama yaitu $50 \mathrm{mg} / 200 \mathrm{grBB}, 100$ $\mathrm{mg} / 200 \mathrm{grBB}$ dan $200 \mathrm{mg} / 200 \mathrm{grBB}$. Hasil penelitian ini diperoleh dari pemeriksaan kadar gula darah menggunakan alat glukometer Easy touch pada kadar gula darah puasa sebelum dan sesudah perlakuan selama 7 hari. Hasil penelitian menunjukkan bahwa terjadi penurunan kadar gula darah pada kelompok perlakuan yang diberikan ekstrak daun senduduk. Pada ekstrak daun senduduk dosis $200 \mathrm{mg} / 200 \mathrm{grBB}$ yang hampir mendakati persentase penurunan kadar gula darah kelompok control positif yaitu sebesar 35\%. Sehingga ekstrak daun senduduk memiliki efek hipoglikemik akan tetapi kemampuan menurunkannya tidak sebesar kemampuan glibenklamid.
\end{abstract}

Kata kunci : ekstrak, daun senduduk (Melastoma malabatricum L), hipoglikemik

Senduduk plant is a versatile plant, ranging from leaves, flowers, and fruit can be used by humans. In the leaves and flowers of sanduduk contain flavonoids, and tannins that serve as antidiabetes which is a disease or chronic metabolic disorder with multietiology characterized by high blood sugar levels. This study aims to determine the effect of lowering blood sugar levels from extracts of leaves and flowers senduduk (Melastoma malabatricum L). This study is a laboratory experimental study. In this study, the subjects were divided into 5 groups, namely $(\mathrm{K}+)$ Glibenchlamide $0.0975 \mathrm{mg}$, (K-) CMC 0.5\%, and the treatment group dose of ethanol extract of sanduduk leaves with the same dose of $50 \mathrm{mg} / 200 \mathrm{grBB}, 100 \mathrm{mg} / 200 \mathrm{grBB}$ and $200 \mathrm{mg} / 200 \mathrm{grBB}$. The results of this study were obtained from the examination of blood sugar levels using Easy Touch glucometer on fasting blood sugar levels before and after treatment for 7 days. The results showed that there was a decrease in blood sugar levels in the treatment group given senduduk leaf extract. In senduduk leaf extract, the dose of 200 $\mathrm{mg} / 200 \mathrm{grBB}$ is almost close to the percentage decrease in blood sugar level of the positive control group, which is $35 \%$. So senduduk leaf extract has a hypoglycemic effect but the ability to reduce it is not as great as the ability of glibenchlamide.

Keywords : extract, senduduk leaf (Melastoma malabatricum L), hypoglycemic 


\section{PENDAHULUAN}

Diabetes adalah penyakit metabolik menahun dan dikenal sebagai pembunuh manusia secara diam-diam atau "silent killer". Seringkali seseorang tidak menyadari kalau dirinya telah menderita diabetes dan begitu mengetahui sudah terjadi komplikasi (Jakhmola \& Tangri, 2012). Diabetes mellitus (DM) tidak dapat disembuhkan tetapi kadar gula darah dapat dikendalikan melalui diet, olah raga, dan obat-obatan. Untuk dapat mencegah terjadinya komplikasi kronis, diperlukan pengendalian DM yang baik (Perkeni, 2011).

Pengobatan DM dapat dilakukan secara non farmakologi dan farmakologi. Pengobatan secara non farmakologi dapat dilakukan dengan olahraga teratur dan diet, sedangkan secara farmakologi pengobatan DM dapat dilakukan dengan penggunaan insulin maupun penggunaan obat-obatan antidiabetes atau lebih dikenal sebagai obat oral (BPOM, 2010). Salah satu obat antidiabetes oral yang paling banyak dikenal adalah glibenklamid dari golongan sulfonilurea yang bekerja menurunkan kadar glukosa darah dengan merangsang sel $\quad \beta$ Langerhans pankreas untuk memproduksi insulin. Oleh sebab itu, syarat pemakaian obat ini adalah pasien dengan pankreas yang masih dapat memproduksi insulin (Ratimanjari, 2011).

Obat hipoglikemik oral (OHO) selain memiliki efikasi yang baik, juga menimbulkan berbagai efek samping seperti diare, pusing sakit kepala, mual muntah,berat badan meningkat dan hipoglikemik (Ndraha, 2014). Dengan begitu perlu adanya alternatif pengobatan penyakit DM yang memiliki efek samping relative kecil.
Beberapa tamanan yang dapat dimanfaatkan sebagai obat diabetes yaitu buah pare (Setiawati, 2012), daun mangga (Sharma dkk, 2013) dan daun senduduk (Joffry dkk, 2012). Kandungan kimia tumbuhan senduduk yang sudah diketahui antara lain saponin, flavonoid dan tanin (Arief, 2011).

Manfaat tanaman senduduk beberapa masyarakat memanfaatkan daun senduduk secara tradisional antara lain dengan cara daun dikunyah, ditumbuk, dan dioleskan pada luka dengan tujuan untuk menghentikan pendarahan. Daun dikonsumsi untuk mengobati infeksi, tekanan darah tinggi dan anti diabetes. Senduduk juga dapat digunakan sebagai obat kumur untuk meredakan sakit gigi. Selain manfaat diatas, digunakan untuk mengobati bisul, tukak lambung, bekas luka, kecing manis, jerawat dan bintik hitam di kulit (Joffry et al, 2012). Oleh karena itu penelitian ini akan mengkaji efek hipoglikemik tanaman senduduk pada tikus putih yang diinduksi DM.

\section{METODE PENELITIAN}

Penelitian ini bersifat eksperimental laboratorium, aecara in vivo dengan menggunakan randomized pre and post test control group design. Penelitian ini dilakukan di Laboratorium Farmakologi STIK Siti Khadijah Palembang pada bulan Mei-Juli 2019. Bahan yang digunakan adalah tanaman senduduk bagian daun. Sampel yang digunakan pada penelitian ini adalah tikus putih jantan galur wistar usia 2-3 bulan, berat badan 150-200 gram. Sampel dipilih dengan menggunakan teknik simple random sampling yang kemudian dibagi menjadi 5 kelompok. Masing-masing tikus diinduksi hiperglikemik dengan diberikan aloksan 
pada dosis $150 \mathrm{mg} / \mathrm{kgBB}$ tikus secara i.p. Setiap kelompok diberi perlakukan berbeda yaitu: kontrol negatif (K-) diberikan CMC, kontrol positif $(\mathrm{K}+)$ diberikan glibenclamid, kelompok perlakuan diberikan ekstrak tanaman senduduk (daun dan bunga) pada dosis 50;100; dan $200 \mathrm{mg} / 200$ gram BB tikus selama 7 hari berturut-turut. Sebelum dan setelah perlakuan dilakukan pemeriksaan kadar gula darah tikus menggunakan glukometer easy touch, selanjutnya dilakukan analisis data.

\section{HASIL}

Pada penelitian ini daun senduduk segar sebanyak $5 \mathrm{~kg}$ diperoleh serbuk simplisia daun senduduk sebanyak 700 gram. Rendemen ekstrak daun senduduk yang di peroleh berupa ekstrak kental yang berwarna hijau kehitaman pekat sebanyak $11 \%$ b/b. Pada esktrak tersebut dilakukan skrining fitokimia ekstrak daun senduduk (Melastoma malabathricum L.) adapun hasilnya dapat dilihat pada tabel 1 .

Tabel 1.

Skrining Fitokimia Daun Senduduk

\begin{tabular}{llc}
\hline \multicolumn{1}{c}{ Metabolit Sekunder } & \multicolumn{1}{c}{ Cara Kerja } & Hasil \\
\hline Tanin & Ekstrak + methanol 3 ml + Fecl hitam kehijauan & + \\
\hline Flavonoid & Ekstrak + NaoH 10\% warna spesifik & + \\
\hline Saponin & Ekstrak + aquadest dididihkan busa & + \\
\hline Terpenoid & Ekstrak + kloroform 1 $\mathrm{ml}+$ asam asetat 1 $\mathrm{ml}+\mathrm{H}_{2} \mathrm{SO}_{4}$ pekat & -
\end{tabular}

Ket : (+) terdapat senyawa metabolit dan (-) tidak terdapat senyawa metabolit

Berdasarkan uji skrining fitokimia yang telah dilakukan pada ekstrak etanol daun senduduk (Melastoma malabatricum L.) menunjukan hasil positif yaitu tanin, flavonoid dan saponin.
Sebelum perlakuan tikus diambil gula darah puasa dengan menggunakan alat glukometer easy touch dengan data sebagai berikut :

Tabel 2.

Kadar Gula Darah Tikus Normal

\begin{tabular}{clc}
\hline Kelompok & \multicolumn{1}{c}{ Perlakuan } & Rerata KGDP (mg/dL) \\
\hline I & Glibenklamid & 108 \\
\hline II & Cmc 0,5\% & 107 \\
\hline III & Ekstrak Daun $50 \mathrm{mg} / 200$ grBB Tikus & 117 \\
\hline IV & Ekstrak Daun $100 \mathrm{mg} / 200$ grBB Tikus & 105 \\
\hline V & Ekstrak Daun $200 \mathrm{mg} / 200$ grBB Tikus & 108 \\
\hline
\end{tabular}

Ket: KGDP (Kadar Gula Darah Puasa)

Pada tabel 2 diatas terlihat rerata kadar gula darah normal tikus tersebut dalam keadaan normal yaitu 105-117 $\mathrm{mg} / \mathrm{dL}$. Hal ini menunjukkan bahwa tikus yang akan digunakan sebagai bahan penelitian tidak mengalami hiperglikemia.
Setelah dilakukan pengambilan kadar gula darah puasa pada tikus, kemudian dilakukan induksi DM dengan aloksan secara i.p. lalu kadar gula darah dicek kembali untuk melihat hasil dengan data sebagai berikut: 
Tabel 3. Rerata Kadar Gula Darah Puasa Tikus DM Sebelum \& Sesudah Perlakuan

\begin{tabular}{clccc}
\hline \multirow{2}{*}{ Kelompok } & \multirow{2}{*}{ Perlakuan } & \multicolumn{3}{c}{ KGDP (mg/dL) } \\
\cline { 3 - 5 } & & $\mathrm{H}_{0}$ & $\mathrm{H}_{3}$ & $\mathrm{H}_{7}$ \\
\hline I & Glibenklamid & 209 & 156 & 131 \\
\hline II & Cmc 0,5\% & 190 & 182 & 169 \\
\hline III & Ekstrak Daun 50 mg/200grBB Tikus & 218 & 164 & 156 \\
\hline IV & Ekstrak Daun 100 mg/200grBB Tikus & 223 & 168 & 154 \\
\hline V & Ekstrak Daun 200 mg/200grBB Tikus & 224 & 176 & 144 \\
\hline
\end{tabular}

$\begin{array}{ll}\text { Ket: } & \mathrm{H}_{0} \text { (Kadar Gula Darah Puasa Tikus DM Sebelum Perlakuan) } \\ & \mathrm{H}_{3} \text { (Kadar Gula Darah Tikus DM Setelah Perlakuan Hari Ke-3) } \\ & \mathrm{H}_{7}(\text { Kadar Gula Darah Tikus DM Setelah Perlakuan Hari Ke-7) }\end{array}$

Pada tabel 3 menunjukan bahwa setelah semua tikus diinduksi aloksan terjadi peningkatan kadar gula darah. Dan pada hari ke-3 dan ke-7 setelah perlakuan, kadar gula darah tikus mengalaimi penurunan kadar gula darah.

Tabel 4. Persentase Penurunan KGDP Tikus Setelah Perlakuan Hari ke-3 dan ke-7

\begin{tabular}{clcc}
\hline Kelompok & \multicolumn{1}{c}{ Pengulangan } & $\mathrm{H}_{3}$ & $\mathrm{H}_{7}$ \\
\hline I & Glibenklamid & $25 \%$ & $37 \%$ \\
\hline II & Cmc 0,5\% & $4,2 \%$ & $11 \%$ \\
\hline III & Ekstrak Daun 50 mg/200grBB Tikus & $24 \%$ & $28 \%$ \\
\hline IV & Ekstrak Daun 100 mg/200grBB Tikus & $24 \%$ & $30 \%$ \\
\hline V & Ekstrak Daun 200 mg/200grBB Tikus & $21 \%$ & $35 \%$ \\
\hline
\end{tabular}

Dari tabel 4, persentase penurunan kadar gula darah diatas dapat dilihat bahwa pemberian ekstrak daun senduduk pada pengecekan hari ke-3 sudah menunjukkan adanya penurunan terhadap kadar gula darah puasa tikus yang diinduksi DM tetapi persentase penurunan di hari ke-3 tidak terlalu besar. Pada hari ke-7 terus terjadi penurunan kadar gula darah puasa. Berdasarkan data pada tabel 4 dapat disimpulkan bahwa ekstrak daun senduduk dengan dosis $200 \mathrm{mg} / 200 \mathrm{grBB}$ memiliki besar persentase penurunan kadar gula darah puasa yang mendekati pada kelompok kontrol positif (glibenklamid).

\section{PEMBAHASAN}

Adanya penurunan kadar glukosa darah pada ekstrak etanol daun senduduk (Melastoma malabathricum L.)diperkirakan karena kandungan dari beberapa senyawa metabolit sekunder yang terdapat didalamnya diantaranya senyawa flavonoid dan saponin. Flavonoid adalah senyawa yang mampu meregenerasi sel beta pankreas dan membantu merangsang sekresi insulin (Dheer dan Bhatnagar, 2010). Mekanisme lain dari flavonoid yang menunjukkan efek hipoglikemik yaitu mengurangi penyerapan glukosa dan mengatur aktivitas ekspresi enzim yang terlibat dalam metabolisme karbohidrat (Brahmachari, 2011). Ada beberapa 
mekanisme kerja obat hipoglikemik oral, yaitu meningkatkan sekresi insulin (golongan sulfonilurea), meningkatkan kepekaan reseptor insulin sehingga absorpsi glukosa di jaringan perifer meningkat, meningkatkan kepekaan insulin jaringan otot, jaringan lemak dan hati, serta menghambat penguraian polisakarida menjadi monosakarida, (Tjay dan Rahadja, 2013) dan disini flavonoid mempunyai mekanisme sama dengan obat hipoglikemik oral golongan sulfonilurea dalam menurunkan kadar glukosa darah tikus dengan cara meningkatkan sekresi insulin pada organ pankreas.

Menurut Ebadi (tahun 2002), senyawa aktif yang juga berperan dalam menurunkan kadar glukosa adalah senyawa kimia golongan saponin. Hasil uji fitokimia ekstrak etanol daun senduduk menunjukkan adanya kandungan senyawa saponin. Saponin memiliki mekanisme kerja yang serupa dengan obat hipoglikemik oral golongan sulfonilurea, dalam menurunkan kadar glukosa darah. Mekanisme kerja sulfonilurea adalah menghambat channel Kalium ATP-ase, sehingga aliran kalium $\left(\mathrm{K}^{+}\right)$ke luar sel menjadi terganggu. Penutupan kanal ini memicu depolarisasi sel- $\beta$ yang akan membuka kanal $\mathrm{Ca}^{2+}$ sehingga menyebabkan peningkatan konsentrasi ion $\mathrm{Ca}^{2+}$ intrasel yang pada gilirannya memicu sekresi insulin. Insulin selanjutnya akan membantu transport glukosa ke dalam selsel lainnya, sehingga menurunkan kadar gula darah.

Berdasarkan hasil penelitian ini dapat disimpulkan bahwa ekstrak etanol daun senduduk memiliki efek hipoglikemik yang mampu menurunkan kadar glukosa darah tikus putih (Rattus norvegicus) jantan galur wistar yang diinduksi aloksan. Diharapkan hasil penelitian ini dapat menjadi informasi awal untuk melakukan penelitian lebih lanjut mengenai kandungan senyawa spesifik yang bertanggung jawab dalam menurunkan kadar glukosa darah sehingga dapat diketahui dengan lebih jelas mekanisme kerja dari ekstrak etanol daun senduduk.

\section{KESIMPULAN}

Ekstrak etanol daun senduduk (Melastoma malabathricum L.) pada dosis $50 \mathrm{mg} / \mathrm{kg} \mathrm{BB}, 100 \mathrm{mg} / \mathrm{kg} \mathrm{BB}$, dan 200 $\mathrm{mg} / \mathrm{kg}$ BB mempunyai efek hipoglikemik terhadap tikus putih jantan galur wistar yang diinduksi aloksan.

\section{SARAN}

Diharapkan hasil penelitian ini dapat menjadi informasi untuk melakukan penelitian lebih lanjut mengenai kandungan senyawa spesifik yang bertanggung jawab dalam menurunkan kadar glukosa darah sehingga dapat diketahui dengan lebih jelas mekanisme kerja dari ekstrak etanol daun daun senduduk (Melastoma malabathricum L).

\section{DAFTAR PUSTAKA}

Badan POM RI, 2010, AcuanSediaan Herbal, Vol. 5, Edisi I, Direktorat Obat Asli Indonesia, BadanPengawasObatdanMakananR epublik Indonesia,Jakarta: BPOM RI

Brahmachari, G., 2011, Bio- Flavonoids With Promising Antidiabetic Potentials: A Critical Survey, Research Signpost, 187-212

Dheer R. \& Bhatnagar P., 2010, A study of the Antidiabetic Activity of Barleria prionitis Linn, Indian 
Journal of Pharmacology, Vol 42 (2): 70-73

Ebadi, M.S. 2002. Pharmacodynamic basis of herbal medicine. CRC Press LLC, Boca Raton

Jakhmola V., Tangri P., 2012. Diabetes Mellitus A Silent Killer : Role of DPP4 Inhibitirs in Treatment. JPSBR. Vol $2: 49$

Joffry SM, Yob NJ, Rofiee MS, Meor MMR, Affandi M, Suhaili Z, Othman F, Akim AM, Desa MNM, Zakaria ZA. (2012).

Melastomamalabathricum

(L.)Smith Ethnomedicinal Uses,

Chemical Constituents, and Pharmacological Properties: A Review. $\quad$ Evidence-Based Complementary and Alternative Medicine.ID 258434: 1-48.

Ndraha, S. 2014. Diabetes Mellitus Tipe 2 dan Tatalaksana Terkini. Depertemen Penyakit Dalam Fakultas Kedokteran Univeritas Krida Wacana Jakarta. Vol (27). No (2).Perkeni. 2011. Konsensus Pengelolaan dan Pencegahan Diabetes Melitus Tipe $2 d i$ Indonesia. Jakarta: PERKENI; 2011

Ratimanjari, D, A. 2011. Efek Penutrunan Kadar Glukosa Darah Dari Infusa Daun Sukun (ArtocarpusAltilis(Park.)Fsb. )Pada Tikus Putih Jantan. Depok: Fakultas Matematika dan Ilmu Pengetahuan Alam.

Setiawati, Ferianis. 2012. Uji fek kstrak tanol 70\% Buah Pare (Momordica Charantia L) Terhadap kadar Gula darah Tikus Putih Jantan Galur Wistar yang Diinduksi Aloksan. Skripsi. Surakarta: Fakultas Kedokteran Universitas Muhammadiyah Surakarta
Sharma, A. 2012.Transdermal Approach of Antidiabetic Drug Glibenclamide: A Review.Internasional Journal of Pharmaceutical Research and Development, Vol. 3 (11), p.25-32.

Tjay, T. H. dan Kirana Rahardja. 2013. Obat-ObatPenting. Jakarta : PT. Alex Media Komputindo. 